\title{
VARIABILIDADE ESPACIAL DO CONFORTO TÉRMICO E A SEGREGAÇÃO SOCIAL DO ESPAÇO URBANO NA CIDADE DE BELÉM, PA.
}

\author{
JOÃO DE ATHAYDES SILVA JÚNIOR ${ }^{1}$, ANTONIO CARLOS LÔLA DA COSTA ${ }^{1}$, JUAREZ CARLOS \\ BRITO PEZZUTI ${ }^{1}$, RAFAEL FERREIRA DA COSTA ${ }^{2}$ \\ ${ }^{1}$ Universidade Federal do Pará (UFPA), Belém, PA, Brasil \\ ${ }^{2}$ Universidade Federal Rural da Amazônia, Campus Parauapebas (UFRA), Parauapebas, PA, Brasil \\ athaydes@ymail.com,lola@ufpa.br,juca@ufpa.br, rfcosta@ymail.com
}

Recebido Maio de 2012 - Aceito Abril de 2013

\begin{abstract}
RESUMO
O presente trabalho vem contribuir com o estudo do clima urbano na cidade de Belém durante a época menos chuvosa, juntamente com uma análise das questões da segregação social deste espaço urbano. Foi realizada uma campanha de coleta de dados meteorológicos durante alguns dias na época menos chuvosa da região para se calcular o índice de conforto térmico nos bairros e compara-los com as tipologias sociais características de cada bairro. Os resultados indicaram que as zonas da cidade menos confortáveis foram a Oeste e a Central, pois são mais urbanizadas e possuem menos vegetação que as demais áreas, enquanto que as zonas mais confortáveis foram a Leste e Noroeste, que possuem mais áreas vegetadas e predominância de edificações baixas. As análises indicaram que não existe um padrão bem definido entre as tipologias sociais dos bairros e suas condições de conforto térmico, pois as características da superfície são mais significativas para as mudanças microclimáticas locais. Palavras-chave: clima urbano, sociedade, segregação social, conforto térmico, Amazônia.
\end{abstract}

\begin{abstract}
SPATIAL VARIABILITY OF THERMAL COMFORT AND SOCIAL SEGREGATION OF URBAN SPACE IN THE CITY OF BELÉM, PA.

This work contributes to the study of urban climate in Belém, PA, during the lesser rainy season, along with an analysis of social segregation issues on urban space. A campaign for collecting meteorological data during the lesser rainy season on the region was made. The data were used to calculate the thermal comfort index inside the neighborhoods and compare them with the characteristic social types in each neighborhood. The results indicated that the West and Central areas of the city were less comfortable, because they are more urbanized and have less vegetation than other areas, while the East and West areas were more comfortable, with more vegetated areas and predominance of low buildings. The analysis indicated that there is not a well-defined pattern between the neighborhoods social types and theirs thermal comfort conditions, because the surface characteristics are more significant to the local microclimate changes.
\end{abstract}

Keywords: urban climate, society, social segregation, thermal comfort, Amazon.

\section{INTRODUÇÃO}

A cidade de Belém está localizada na região Amazônica e posicionada estrategicamente na foz do Rio Amazonas, e devido a sua importância histórica e privilegiada localização geográfica a cidade foi um ponto de apoio fundamental para a conquista da Amazônia, além de lhe render um grande desenvolvimento econômico e urbano. Por ficar distante dos outros centros urbanos ao sul do país, tornou-se um ponto de referência na região, principalmente, durante o ciclo da borracha, onde o transporte e a exportação eram realizados através dos seus portos (Cardoso, 2007; Dias e Dias, 2007; Ponte 2003).

Na década de 1950 houve a intervenção do Estado na região Amazônica através do Plano de Desenvolvimento Nacional (PDN), com a construção de Brasília e as primeiras 
estradas, e no final dos anos 1960 os governos militares dedicaram especial atenção à ocupação estratégica da Amazônia, onde grandes mudanças começaram a ocorrer na região, como por exemplo, a implantação de grandes projetos de mineração, hidroelétricos e abertura de estradas, com intuito de desenvolver economicamente a região Norte do Brasil (Martins, 1982). Após a abertura e inauguração da BR-010 (Rodovia Belém-Brasília), a penetração e colonização da região ficaram mais fáceis. Segundo Hogan (2001), um rápido processo de urbanização reflete a existência de um contingente de trabalhadores subempregados ou desempregados, que migraram para a região, além de um crescimento urbano carente de planejamento. Entre os anos de 1960 e 1990, a cidade de Belém experimentou um forte crescimento populacional, o que aumentou a pressão sobre os recursos naturais, sobre os espaços existentes na cidade, especificamente nas regiões de baixadas, devido ao déficit habitacional. Segundo Castells (1989), este déficit se constitui em um grave problema que afeta a população, principalmente, quando ocorrem grandes mudanças territoriais. Com o crescimento populacional e o déficit habitacional, a população tende a organizar-se no espaço intra-urbano, e devido à habitação ser resultado de um processo produtivo, ela é responsável por boa parte dessa organização em sítios sociais, (Castells, 1989; Villaça, 2001).

De acordo com Barbirato (2010), a realização de pesquisas sobre o clima de uma localidade é uma ferramenta fundamental para o planejamento urbano, no entanto, muitas vezes esse fator é ignorado devido ao crescimento desordenado das cidades, o que implica na não criação de espaços mais confortáveis termicamente para a população. $\mathrm{O}$ crescimento desordenado das áreas urbanas vai gerar alterações nos padrões climáticos daquela região devido às alterações ambientais, principalmente, pelas mudanças das características da cobertura do solo, o que pode gerar o surgimento de microrregiões termicamente desconfortáveis (Maitelli et al., 1991; Goldreich, 1992; Jáuregui, 1992). As condições do conforto térmico são funções das atividades desenvolvidas pelo indivíduo, das suas vestimentas e das variáveis ambientais que proporcionam as trocas de calor entre o corpo e o ambiente (Fanger, 1972). A identificação e quantificação dos fenômenos climáticos urbanos e das características térmicas de uma cidade, assim como, a sua correlação com diversos outros fatores, mostra-se de grande importância no sentido de dar subsídio a projetos de planejamento urbano, favorecendo a melhoria da qualidade de vida de seus habitantes. Nesse estudo será analisada a distribuição espacial do conforto térmico em diferentes regiões na cidade de Belém e avaliar, sob o ponto de vista climático, se as condições térmicas destas regiões estão relacionadas com as tipologias sócio-ocupacionais dos sítios sociais.

\section{MATERIAIS E MÉTODOS}

\subsection{Caracterização do local de estudo e aquisição de informações}

A Cidade de Belém, capital do Estado do Pará, está localizada em uma região tropical na porção oriental da Amazônia, e teve no passado, um papel importante na ocupação dessa região, o que contribuiu, significativamente, para o seu crescimento, tendo atualmente uma população de 1.393.399 habitantes (IBGE, 2010). A cidade faz divisa com o município de Ananindeua ao Leste, com o Rio Guamá ao Sul, com a Baia do Guajará ao Oeste e ao norte com a Baia do Marajó, conforme ilustrado na Figura 1.

O clima em Belém, segundo a classificação de Köppen (1900-1936) é do tipo Am, ou seja, clima tropical chuvoso de monção, com a média anual da temperatura do ar de $26,0 \pm$ $0,4{ }^{\circ} \mathrm{C}$, com máximas e mínimas variando de $31,5 \pm 0,7^{\circ} \mathrm{C}$ a $22,0 \pm 0,3{ }^{\circ} \mathrm{C}$, respectivamente, durante $\mathrm{o}$ ano. A pluviosidade média anual é de 2.858,7 $\pm 76,6 \mathrm{~mm} /$ ano com maior volume no período chuvoso (dezembro a maio), correspondendo a 71,2\% do total anual, enquanto que os $28,8 \%$ restantes são distribuídos nos meses de junho a novembro (Costa, 1998; Silva Junior et al., 2012).

Os dados meteorológicos foram coletados utilizando 08 microloggers modelo HOBO U10, da Onset, que são equipamentos que medem e registram a temperatura e a umidade relativa do ar, que foram programados para realizar as leituras e gravações a cada 30 minutos, no período das 06 às 19 horas. Os microloggers foram instalados no interior de abrigos adequados para proteger os sensores da radiação solar direta e que permitisse uma ventilação adequada, e antes de serem utilizados em campo os mesmos foram aferidos junto a uma Estação Meteorológica Automática (EMA) e também, posteriormente, após sua retirada.

Foram utilizadas informações de uma EMA da marca CampbellSci, que registrou os dados de temperatura e umidade relativa do ar a cada 30 minutos, estando esta EMA localizada em uma área central da cidade. As localizações dos pontos de coleta de dados estão ilustrados na Tabela 1. Utilizaram-se também dados das estações meteorológicas (automática e convencional) do Instituto Nacional de Meteorologia (INMET) e do Aeroporto Internacional de Belém. A coleta dos dados ocorreu nos dias 17 a 19 de novembro de 2010, simultaneamente em locais previamente selecionados em diferentes bairros da cidade, das 06 às 19 horas, de forma a contrastarem suas características de cobertura do solo, sociais e ambientais, e o Índice de Calor (IC) foi calculado neste mesmo intervalo. 


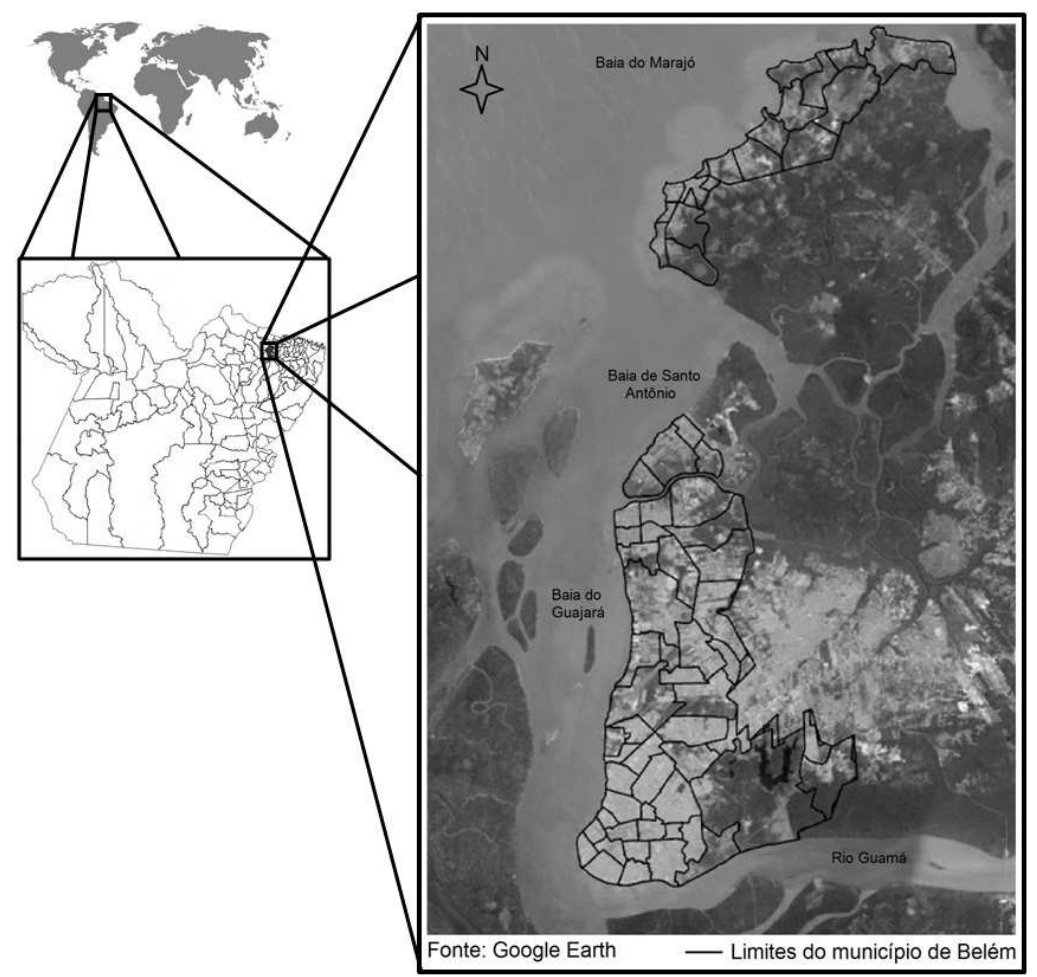

Figura 1 - Localização da cidade de Belém, PA.

Tabela 1 - Locais de coleta de dados meteorológicos na cidade de Belém.

\begin{tabular}{cl}
\hline Ponto & \multicolumn{1}{c}{ Local } \\
\hline P-01 & $\begin{array}{l}\text { Travessa Quintino Bocaiuva, no cruzamento com a Avenida Nazaré, no bairro de } \\
\text { Nazaré, zona central da cidade. }\end{array}$ \\
P-02 & $\begin{array}{l}\text { Travessa Padre Eutíquio, no cruzamento com a Avenida Alcindo Cacela, no bairro da } \\
\text { Condor, zona sul da cidade. }\end{array}$ \\
P-03 & $\begin{array}{l}\text { Avenida Conselheiro Furtado, no cruzamento com a Avenida Alcindo Cacela, no } \\
\text { bairro da Cremação, zona sul da cidade. } \\
\text { Avenida Almirante Barroso, no cruzamento com a Travessa Humaitá, no bairro do }\end{array}$ \\
P-04 & $\begin{array}{l}\text { Marco, área central da cidade. } \\
\text { Avenida Pedro Miranda, no cruzamento com a Travessa Maurití, no bairro da }\end{array}$ \\
P-05 & $\begin{array}{l}\text { Pedreira, zona oeste da cidade. } \\
\text { Rua Gaspar Viana, na Praça das Mercês, no bairro da Campina, zona central da } \\
\text { cidade. } \\
\text { Avenida José Bonifácio, no bairro de São Brás, na área da Companhia de } \\
\text { P-07 }\end{array}$ \\
S-08 & $\begin{array}{l}\text { Avenida Júlio Cesar, Aeroporto Internacional de Belém, no bairro de Val-de-Cães, } \\
\text { zona oeste da cidade. } \\
\text { Avenida Senador Lemos, no cruzamento com a Avenida Doutor. Freitas, no bairro da }\end{array}$ \\
P-09 & $\begin{array}{l}\text { Sacramenta, zona oeste da cidade. } \\
\text { Estrada da Ceasa, no bairro do Curió-Utinga, Estação Meteorológica Convencional } \\
\text { do INMET, zona leste da cidade. }\end{array}$ \\
P-10 & $\begin{array}{l}\text { Avenida Almirante Barroso, no bairro da Castanheira, Estação Meteorológica } \\
\text { Automática do INMET, zona leste da cidade. }\end{array}$ \\
P-11
\end{tabular}




\section{2 Índice de conforto térmico}

Os índices de conforto térmico foram desenvolvidos com base na necessidade de aumentar o rendimento do trabalho durante a revolução industrial, para determinar a influência das condições da temperatura e umidade relativa do ar no rendimento do trabalho físico dos operários, e também situações especiais de guerra, quando as tropas são deslocadas para regiões de diferentes tipos de clima. O conforto térmico foi definido pela ISO 7730 como "um estado de espírito que expressa satisfação com o ambiente que envolve uma pessoa", logo é uma percepção subjetiva que vai depender dos aspectos fisiológicos e emocionais dos indivíduos. Os índices de conforto térmico procuram integrar o efeito conjunto de algumas variáveis, levando em consideração a atividade exercida, as indumentárias e as variáveis ambientais para diferentes condições que o indivíduo pode ser submetido (Frota e Schiffer, 2001).

Neste estudo foi utilizado o Índice de Calor (IC), derivado do índice humidex desenvolvido por George Winterling em 1978 e posteriormente adaptado com base no trabalho de Steadman (1979). O IC foi elaborado a partir de medidas subjetivas de quanto calor se sente para dados valores de temperatura e umidade relativa do ar, nas situações em que as temperaturas estão elevadas, estando a pessoa à sombra em condições de vento fraco.

O IC foi calculado através da Equação 1 sendo aplicadas algumas correções, quando necessárias. Quando a umidade relativa do ar é inferior a $13 \%$ e a temperatura encontra-se entre $26,66{ }^{\circ} \mathrm{C}$ e $44,44^{\circ} \mathrm{C}$, então subtrai-se o valor encontrado na Equação 2 do valor da Equação 1. No entanto, se a umidade relativa do ar for superior a $85 \%$ e a temperatura estiver entre $26,66^{\circ} \mathrm{C}$ e $30,55^{\circ} \mathrm{C}$, o valor encontrado na Equação 3 é somado ao valor da Equação 1. Quando os valores da temperatura e umidade relativa do ar não se enquadrarem nas duas opções de ajuste é porque não existe a necessidade de fazê-los. Os níveis de alerta e suas consequências à saúde humana estão ilustrados na Tabela 2 .

A expressão para cálculo do IC à sombra é dada por:

$$
\begin{aligned}
I C= & -42,379+2,04901523 \times T+10,14333127 \times U R \\
& -0,22475541 \times T \times U R \quad-6,83783 \times 10^{-3} \times T^{2} \\
& -5,481717 \times 10^{-2} \times U R^{2}+1,22874 \times 10^{-3} \times T^{2} \times U R \\
& +8,5282 \times 10^{-4} \times T \times U R^{2}-1,99.10^{-6} \times U R^{2}
\end{aligned}
$$

onde, $\mathrm{T}$ é a temperatura do bulbo seco $\left({ }^{\circ} \mathrm{F}\right)$ e UR é a umidade relativa do ar (\%).

$$
\begin{aligned}
& \text { AJUSTE }=[(13-U R) / 4] \times \sqrt{\{[17-|(T-95)|] / 17\}} \\
& \text { AJUSTE }=[(U R-85) / 10] \times[(87-T) / 5]
\end{aligned}
$$

Com os resultados obtidos após o cálculo do IC, foi utilizado um software para interpolar os valores para o restante da cidade através do processo de krigagem baseado em equações lineares, e para minimizar os efeitos de borda, foram utilizadas informações de estações meteorológicas situadas nos municípios de Barcarena, Soure e Castanhal, que são vizinhos a Belém. A interpolação espacial dos pontos pelo método da Kriging foi adotada por produzir melhores estimativas, pois é embasada na não tendenciosidade do estimador e na variância mínima das estimativas, além de apresentar uma ótima qualidade estatística, conforme resultados apresentados por Mello et al. (2003).

\begin{tabular}{|c|c|c|}
\hline Nível de Alerta & Índice de Calor & Sintomas \\
\hline Perigo Extremo & $54^{\circ} \mathrm{C}$ ou mais & $\begin{array}{l}\text { Insolação; risco de acidente vascular cerebral (AVC) } \\
\text { iminente. }\end{array}$ \\
\hline Perigo & $41,1^{\circ} \mathrm{C}-54{ }^{\circ} \mathrm{C}$ & $\begin{array}{l}\text { Câimbras, insolação, esgotamento físico. Possibilidade } \\
\text { de danos cerebrais (AVC) para exposições prolongadas } \\
\text { com atividades físicas. }\end{array}$ \\
\hline Cautela Extrema & $32,1^{\circ} \mathrm{C}-41{ }^{\circ} \mathrm{C}$ & $\begin{array}{l}\text { Possibilidade de câimbras, de esgotamento físico e } \\
\text { insolação para exposições prolongadas e atividades } \\
\text { físicas. }\end{array}$ \\
\hline Cautela & $27,1^{\circ} \mathrm{C}-32^{\circ} \mathrm{C}$ & $\begin{array}{l}\text { Possível fadiga em casos de exposições prolongadas e } \\
\text { prática de atividades físicas. }\end{array}$ \\
\hline Não há alerta & $\mathrm{IC}<27^{\circ} \mathrm{C}$ & Não há problemas \\
\hline
\end{tabular}

\subsection{A estratificação social do espaço urbano na cidade de Belém}

Segundo Oliveira et al. (2005), o processo de segregação urbana na cidade de Belém é antigo, e data da época de fundação

Tabela 2 - Níveis de alerta e suas consequências a saúde humana.

Fonte: Adaptado de National Weather Service, Weather Forecast Office, NOAA. 
da cidade, onde as instituições que conduziram a fundação da mesma instalaram-se nas melhores áreas, as mais elevadas, enquanto que as famílias desprovidas de posses foram ocupar as áreas mais baixas, sujeitas a alagamentos, e essa configuração de segregação existiu por um longo período, baseando-se nas áreas centrais e na cota dos terrenos da cidade.

A segregação urbana foi definida por Castells (1983) como "uma tendência à organização do espaço em zonas de forte homogeneidade social interna e com intensa disparidade social entre elas, sendo esta disparidade compreendida não só em termos de diferença, como também de hierarquia". Ou seja, a segregação socioespacial é uma tendência de agrupamento no espaço de grupos sociais homogêneos, que derivam de uma disparidade social proclamada na organização do território, sendo também a expressão dos processos de reprodução do trabalho vinculada com a estrutura social (Dumke, 2007). Segundo a afirmação de Castells (1983), a estratificação e a segregação urbana não são responsáveis diretas pelo sistema de estratificação social no espaço urbano, mas articulam-se ao seu processo de produção como forma de distribuição dos seus indivíduos, explicando que "cada conjuntura histórica especifica o tipo de urbanização e a segregação do espaço". Villaça (2001) definiu a segregação das classes sociais como "um processo segundo o qual diferentes classes ou camadas sociais tendem a se concentrar cada vez mais em diferentes regiões gerais ou conjuntos de bairros da metrópole".

Essa situação descrita por estes autores pode ser observada em diversas áreas de Belém, e uma das formas de enxergar é através dos custos para habitar-se determinados locais, dos aspectos físicos e estéticos dos imóveis e da sua localização geográfica no espaço intra-urbano.

Nas ultimas décadas, devido ao grande crescimento populacional, as famílias mais privilegiadas economicamente que não conseguiram se instalar nas áreas centrais, começaram a ocupar edifícios de alto padrão em áreas mais afastadas do centro, e com estas mudanças as áreas passaram a ficar mais valorizadas, gerando mais atrativos para migrações para estas áreas. Segundo Palheta Junior (2005), a migração dentro de Belém, ocorre devido à insatisfação com o imóvel anteriormente ocupado, a localização do imóvel, por causa de fatores como a qualidade do bairro e dos serviços nele existentes e também do nível de renda do indivíduo.

A pesquisa desenvolvida por Cardoso et al. (2006), também constatou a existência da segregação socioespacial na cidade de Belém, estudo esse realizado com base na metodologia desenvolvida pelo Observatório das Metrópoles auxiliada com dados dos censos do IBGE, onde foram estabelecidas hierarquias sociais baseadas em classes, que possuem recursos e que não possuem recursos; que exercem trabalho manual e não manual; trabalho formal e informal e entre os setores econômicos (secundário x terciário; moderno x tradicional). A metodologia utilizada por Cardoso (2007), também analisou outros dois aspectos complementares, a separação espacial das áreas devido a segregação social e a homogeneidade e heterogeneidade entre os habitantes de cada área. Foram definidas as tipologias Superior (dirigentes e profissionais de ensino superior), Médio (classe média, comerciantes, setores médios ou acima da media metropolitana, operários e populares) e Popular (operários diversos, trabalhadores não especializados e o subproletariado). A classificação das áreas a partir de tipologias sócio-ocupacionais, utilizada neste estudo, foi baseada nos trabalhos de Cardoso et al. (2006), Cardoso (2007) e Lima e Moysés (2009), e que se subdivide em oito tipologias: Popular, Popular Periférica, Popular Operária, Operário, Médio, Médio Inferior, Médio Superior e Superior, apresentadas na Tabela 3 .

\section{RESULTADOS E DISCUSSÕES}

Na Tabela 4 encontra-se ilustrada a descrição das tipologias sócio-ocupacionais dos bairros na cidade de Belém e o respectivo valor do IC para cada um deles. Em média, a zona Oeste apresentou o menor conforto térmico na cidade, seguida pelas zonas Central, Sul, Norte, Nordeste, Noroeste e Leste, com valores médios do IC de $29,3{ }^{\circ} \mathrm{C} ; 29,2{ }^{\circ} \mathrm{C} ; 29,1$ ${ }^{\circ} \mathrm{C} ; 29,0{ }^{\circ} \mathrm{C} ; 28,8^{\circ} \mathrm{C} ; 28,7{ }^{\circ} \mathrm{C} ; 28,7{ }^{\circ} \mathrm{C}$, respectivamente, onde as tipologias socioespaciais predominantes nessas zonas são Oeste (Operário), Central (Superior), Sul (Operária), Norte (Popular Operária), Nordeste (Popular Periférica), Noroeste (Médio Inferior) e Leste (Operário). O local que apresentou o maior valor do IC registrado foi o bairro do Marco com um valor médio de $30,0^{\circ} \mathrm{C}$.

$\mathrm{Na}$ Figura 2 estão ilustradas as médias diurnas (06h às 19h) do IC para o município de Belém enfatizando os bairros por zonas. Observou-se que existem áreas bastante distintas, com relação ao conforto térmico, com valores máximos, médios e mínimos do IC de $30,0{ }^{\circ} \mathrm{C}, 28,9^{\circ} \mathrm{C}$ e $27,4{ }^{\circ} \mathrm{C}$, respectivamente durante o dia. Com base nas faixas de alerta ilustradas na Tabela 2 , observa-se que toda a cidade fica dentro da faixa de cautela no período diurno. No entanto, quanto maior o valor alcançado pelo IC, maior será o desconforto térmico experimentado pela população. Os bairros de Belém por possuírem características físicas de uso do solo, morfológicas e de ocupação distintas, os valores do IC variaram.

Uns dos elementos urbanos que exercem uma grande influência nessa variação do conforto térmico são a vegetação e a morfologia urbana, onde o primeiro possui uma função muito importante, pois é responsável pela atenuação e absorção de parte dos raios solares, além de produzir o sombreamento, e o segundo, pois irá influenciar na circulação do vento, na 
evaporação, além do sombreamento causado pelas edificações e a proximidade dos rios. Com o projeto de urbanização realizado durante a gestão de Antônio Lemos (1897 - 1912), dentro da primeira Légua Patrimonial (Área doada pelo Rei de Portugal em 1627 à Câmara Municipal de Belém, através de carta de doação de sesmaria), avenidas foram abertas e houve a preocupação com o plantio de espécies arbóreas no decorrer dessas principais avenidas da época, e essas áreas estavam localizadas nas áreas centrais da cidade, como a Avenida Presidente Vargas, Avenida Nazaré, Avenida Gov. José Malcher e a Avenida Gentil Bittencourt. Por serem áreas centrais e terem sido urbanizadas primeiro que outras áreas, as mesmas sofreram um processo maior de valorização. No eixo dessas Avenidas foram plantadas grandes quantidades de mangueiras (mangifera indica L.), que atualmente colaboram para atenuar a incidência dos raios solares à superfície, e juntamente com o sombreamento dos edifícios, tornam essas áreas menos desconfortáveis termicamente, apesar de estarem situadas em uma área central da cidade.

$\mathrm{Na}$ zona Leste da cidade predominam os bairros com as tipologias sociais Popular, Operário e Médio. O bairro do Curió-Utinga $\left(\mathrm{N}^{\circ} 10\right)$ foi o menos desconfortável termicamente, fato este atribuído à Área de Proteção Permanente (APA) de Belém e instituições públicas que ocupam quase toda extensão deste bairro, com o valor do $\mathrm{IC}$ de $27,4^{\circ} \mathrm{C}$. Os demais bairros da zona leste são bastante urbanizados, e não possuem edifícios muito altos, com uma pequena quantidade de áreas vegetadas, o que ocasionou menos conforto térmico do que no bairro do Curió-Utinga.

Já na zona Sul da cidade predominam os bairros com a tipologia social Operário e Popular, onde os valores do IC variaram entre $29,0{ }^{\circ} \mathrm{C}$ e $29,8^{\circ} \mathrm{C}$. Os bairros do Jurunas $\left(\mathrm{N}^{\circ}\right.$ $44)$ e Condor $\left(\mathrm{N}^{\circ} 45\right)$ são bastante populosos e apresentaram valores de desconforto térmico com o IC de $29,8^{\circ} \mathrm{C}$ e $28,9^{\circ} \mathrm{C}$, respectivamente. Esses bairros estão situados nas margens do Rio Guamá, que possuem diversos portos privados, existe pouca vegetação arbórea, onde a altura predominante das residências são de dois pavimentos, construídas em alvenaria e/ou madeira.

$\mathrm{Na}$ zona central da cidade predominam os bairros com tipologia social Superior, esta área da cidade foi a primeira a ser ocupada historicamente, devido a sua localização estratégica por estar nas margens do Rio Guamá e da Baía do Guajará, e as condições do terreno serem melhores (mais elevados e sem

Tabela 3 - Caracterização das tipologias sócio-ocupacionais.

\begin{tabular}{|c|c|}
\hline Tipologia & Descrição característica \\
\hline Popular Periférica & $\begin{array}{l}\text { Esta categoria ocupacional possui uma maior representatividade pelos } \\
\text { trabalhadores domésticos, biscateiros e agricultores. }\end{array}$ \\
\hline Popular & $\begin{array}{c}\text { Esta categoria ocupacional possui uma maior representatividade pelos } \\
\text { operários da construção civil, seguidos por trabalhadores do comércio, } \\
\text { trabalhadores domésticos e biscateiros. }\end{array}$ \\
\hline Popular Operária & $\begin{array}{l}\text { Esta categoria ocupacional possui uma maior representatividade de } \\
\text { prestadores de serviço não especializados, seguidos por trabalhadores da } \\
\text { indústria moderna e tradicional e operários da construção civil.. }\end{array}$ \\
\hline Operária & $\begin{array}{l}\text { Esta categoria ocupacional possui uma maior representatividade de } \\
\text { trabalhadores do comércio e prestadores de serviços especializados, } \\
\text { seguidos de prestadores de serviços não especializados. }\end{array}$ \\
\hline Média Inferior & $\begin{array}{l}\text { Esta categoria ocupacional possui uma maior representatividade de } \\
\text { trabalhadores da indústria moderna e tradicional e operários de serviços } \\
\text { auxiliares, seguidos de profissionais autônomos de nível superior. }\end{array}$ \\
\hline Média & $\begin{array}{l}\text { Esta categoria ocupacional possui uma maior representatividade por } \\
\text { profissionais da área de saúde e educação, seguidas das ocupações } \\
\text { artísticas, técnicas e de segurança pública. }\end{array}$ \\
\hline Média Superior & $\begin{array}{l}\text { Esta categoria ocupacional possui uma maior representatividade por } \\
\text { ocupações que envolvem a segurança pública, justiça e correios, seguida } \\
\text { pelos grandes empregadores, dirigentes do setor público e privado. }\end{array}$ \\
\hline Superior & $\begin{array}{c}\text { Essa tipologia é representada pelos grandes empregadores, dirigentes do } \\
\text { setor público e privado, pequenos empregadores, ocupações artísticas e } \\
\text { profissionais de nível superior e professores. }\end{array}$ \\
\hline
\end{tabular}

Fonte: Lima e Moyses, (2009). 
Tabela 4 - Descrição das tipologias sociais dos bairros na cidade de Belém com seus respectivos valores médios do IC e suas localizações por zonas.

\begin{tabular}{|c|c|c|c|c|c|c|c|c|c|}
\hline $\mathrm{N}^{\mathrm{o}}$ & Bairro & Tipologia & $\begin{array}{c}\mathrm{IC} \\
\left({ }^{\circ} \mathrm{C}\right)\end{array}$ & Zona & $\mathrm{N}^{\mathrm{o}}$ & Bairro & Tipologia & $\begin{array}{c}\mathrm{IC} \\
\left({ }^{\circ} \mathrm{C}\right)\end{array}$ & Zona \\
\hline 01 & $\begin{array}{l}\text { Cidade } \\
\text { Velha }\end{array}$ & $\mathrm{S}$ & 29,3 & $\mathrm{C}$ & 26 & $\begin{array}{l}\text { Ilha de } \\
\text { Mosqueiro }\end{array}$ & PP & 29,0 & $\mathrm{NE}$ \\
\hline 02 & $\begin{array}{l}\text { Batista } \\
\text { Campos }\end{array}$ & S & 29,3 & $\mathrm{C}$ & 27 & Paracuri & MI & 28,8 & NO \\
\hline 03 & Campina & $\mathrm{S}$ & 29,6 & $\mathrm{C}$ & 28 & Ponta Grossa & MI & 28,8 & $\mathrm{NO}$ \\
\hline 04 & Reduto & $\mathrm{S}$ & 29,3 & $\mathrm{C}$ & 29 & Agulha & MI & 28,8 & NO \\
\hline 05 & Nazaré & S & 28,7 & $\mathrm{C}$ & 30 & Parque Guajará & $\mathrm{P}$ & 28,8 & NO \\
\hline 06 & São Braz & S & 28,5 & $\mathrm{C}$ & 31 & Tenoné & $\mathrm{PO}$ & 28,8 & NO \\
\hline 07 & Umarizal & $\mathrm{S}$ & 29,3 & $\mathrm{C}$ & 32 & Águas Negras & $\mathrm{PO}$ & 28,8 & $\mathrm{NO}$ \\
\hline 08 & Fátima & M & 28,5 & $\mathrm{C}$ & 33 & Maracacuera & $\mathrm{PO}$ & 28,5 & $\mathrm{NO}$ \\
\hline 09 & Marco & M & 30,0 & $\mathrm{C}$ & 34 & $\begin{array}{l}\text { Campina de } \\
\text { Icoaraci }\end{array}$ & MI & 28,8 & $\mathrm{NO}$ \\
\hline 10 & $\begin{array}{l}\text { Curió- } \\
\text { Utinga }\end{array}$ & $\mathrm{O}$ & 27,4 & $\mathrm{~L}$ & 35 & Cruzeiro & MI & 28,8 & $\mathrm{NO}$ \\
\hline 11 & Aura & $\mathrm{O}$ & 28,3 & $\mathrm{~L}$ & 36 & Ilha de Outeiro & PP & 28,3 & $\mathrm{NO}$ \\
\hline 12 & $\begin{array}{l}\text { Águas } \\
\text { Lindas }\end{array}$ & $\mathrm{O}$ & 28,3 & $\mathrm{~L}$ & 37 & Pedreira & $\mathrm{P}$ & 29,4 & $\mathrm{O}$ \\
\hline 13 & Guanabara & $\mathrm{O}$ & 28,5 & $\mathrm{~L}$ & 38 & Telegrafo & M & 29,3 & $\mathrm{O}$ \\
\hline 14 & Castanheira & $\mathrm{O}$ & 29,0 & $\mathrm{~L}$ & 39 & Barreiro & $\mathrm{O}$ & 29,5 & $\mathrm{O}$ \\
\hline 15 & Souza & $\mathrm{P}$ & 29,5 & $\mathrm{~L}$ & 40 & Sacramenta & $\mathrm{O}$ & 29,8 & $\mathrm{O}$ \\
\hline 16 & Marambaia & $\mathrm{P}$ & 29,3 & $\mathrm{~L}$ & 41 & Maracangalha & $\mathrm{O}$ & 29,5 & $\mathrm{O}$ \\
\hline 17 & Mangueirão & $\mathrm{P}$ & 29,3 & $\mathrm{~L}$ & 42 & Val de Cães & $\mathrm{P}$ & 28,4 & $\mathrm{O}$ \\
\hline 18 & Una & M & 28,8 & $\mathrm{~N}$ & 43 & Miramar & $\mathrm{O}$ & 29,3 & $\mathrm{O}$ \\
\hline 19 & Bengui & $\mathrm{O}$ & 29,3 & $\mathrm{~N}$ & 44 & Jurunas & $\mathrm{O}$ & 29,8 & $\mathrm{~S}$ \\
\hline 20 & $\begin{array}{l}\text { São } \\
\text { Clemente }\end{array}$ & $\mathrm{PO}$ & 29,3 & $\mathrm{~N}$ & 45 & Condor & $\mathrm{O}$ & 29,7 & S \\
\hline 21 & $\begin{array}{l}\text { Parque } \\
\text { Verde }\end{array}$ & $\mathrm{O}$ & 29,0 & $\mathrm{~N}$ & 46 & Guamá & $\mathrm{O}$ & 29,0 & S \\
\hline 22 & Coqueiro & M & 28,8 & $\mathrm{~N}$ & 47 & Cremação & MS & 28,8 & S \\
\hline 24 & Pratinha & $\mathrm{PO}$ & 29,0 & $\mathrm{~N}$ & 48 & Terra firme & $\mathrm{P}$ & 28,8 & S \\
\hline 24 & Tapanã & $\mathrm{PO}$ & 28,8 & $\mathrm{~N}$ & 49 & Universitário & $\mathrm{O}$ & 28,5 & $\mathrm{~S}$ \\
\hline 25 & Cabanagem & $\mathrm{P}$ & 28,8 & $\mathrm{~N}$ & 50 & Canudos & M & 28,8 & $\mathrm{~S}$ \\
\hline
\end{tabular}

P (Popular); PP (Popular Periférica); PO (Popular Operária); O (Operária); M (Média); MI (Média Inferior); MS (Média Superior); S (Superior).

várzea), e posteriormente, a cidade cresceu em direção aos outros bairros mais afastados do rio. Esta área, atualmente, é a mais verticalizada da cidade e o efeito do sombreamento, tanto dos edifícios como das árvores, ajudam a amenizar o desconforto térmico para os pedestres. O bairro de Nazaré $\left(\mathrm{N}^{\circ} 05\right)$ que possui muitos edifícios e vegetação arbórea no decorrer das avenidas, apresentou um valor de IC $28,7^{\circ} \mathrm{C}$, enquanto que, o bairro do Umarizal ( $\mathrm{N}^{\circ}$ 07) que é bastante verticalizado, mas pouco arborizado, o valor do IC encontrado foi de $29,3{ }^{\circ} \mathrm{C}$.
$\mathrm{Na}$ zona Oeste da cidade predominam os bairros com as tipologias sociais Operário e Popular, com a predominância de construções baixas com dois a três pavimentos, e alguns edifícios. O bairro da Sacramenta ( $\left.{ }^{\circ} 40\right)$ que é bastante populoso e possui poucas áreas vegetadas, o IC encontrado foi de $29,8^{\circ} \mathrm{C}$, enquanto que, no bairro de Val-de-Cães $\left(\mathrm{N}^{\circ} 42\right)$, o valor do IC registrado foi de $28,4{ }^{\circ} \mathrm{C}$, fato este associado as proximidades das áreas vegetadas no entorno do aeroporto. Já no bairro da Pedreira, a presença de vegetação é pequena e o 
IC encontrado foi de $29,4^{\circ} \mathrm{C}$, e este bairro é uma área que está passando por um processo de verticalização nos últimos anos, devido à saturação do espaço na área central da cidade, conforme explica Oliveira et al. (2005).

$\mathrm{Na}$ zona Norte da cidade predominam os bairros com as tipologias sociais Popular Operário, Operário e Médio. Essa região é caracterizada por edificações baixas, diversos conjuntos residenciais, sendo alguns de alto padrão. Ao longo do eixo da Avenida Augusto Montenegro, via de grande importância para a região, por ainda existirem terrenos disponíveis, está havendo uma expansão para essa direção, com a construção de diversos condomínios verticais e de casas de alto padrão. Os bairros do Benguí $\left(\mathrm{N}^{\circ} 19\right)$ e Tapanã ( $\left.\mathrm{N}^{\circ} 24\right)$ apresentaram valores de IC de $29,3{ }^{\circ} \mathrm{C}$ e $28,8^{\circ} \mathrm{C}$, respectivamente, uma variação bastante pequena, sendo que, o bairro do Tapanã encontra-se nas margens de um grande corpo hídrico, enquanto que o Benguí está mais afastado da margem da baía do Guajará.

Nas zonas Nordeste e Noroeste da cidade as tipologias sociais predominantes foram são a Popular Periférico, Médio Inferior e Popular Operário. A zona Nordeste que é composta

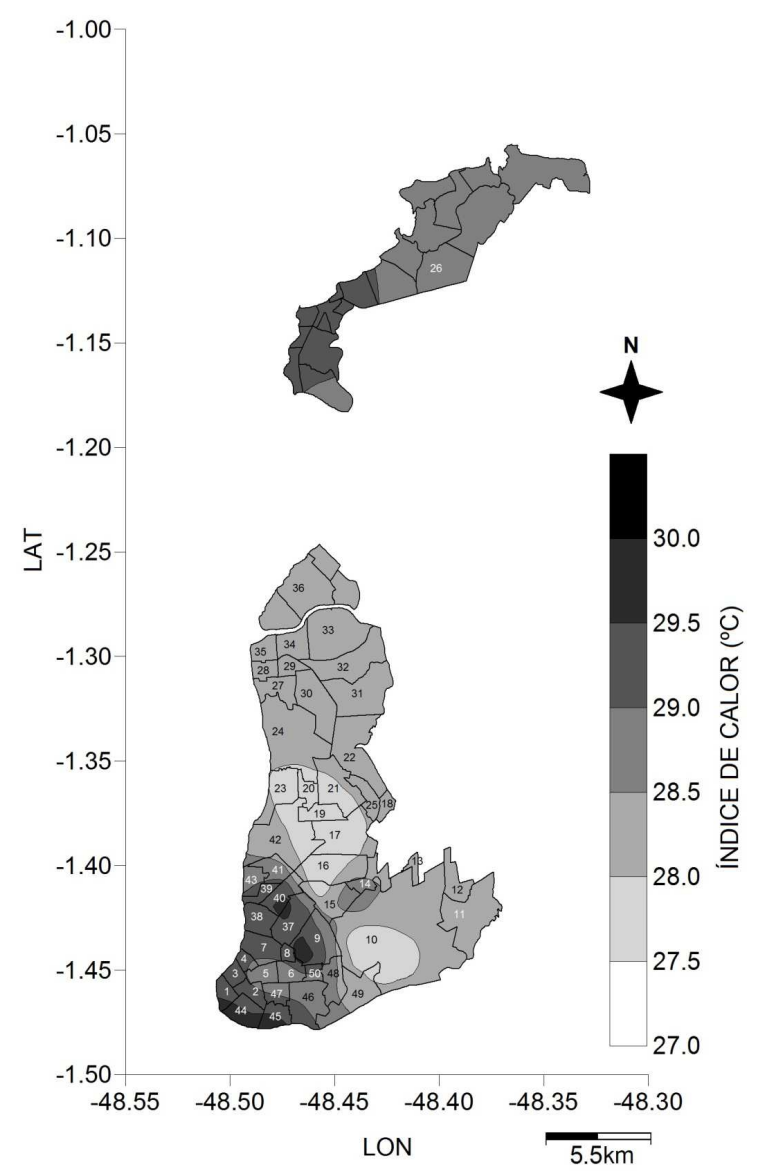

Figura 2 - Distribuição espacial do Índice de Calor na Cidade de Belém, PA. pela Ilha de Mosqueiro ( $\left.\mathrm{N}^{\circ} 26\right)$, onde predominam edificações baixas, apresentou um IC de $29,0^{\circ} \mathrm{C}$. A Ilha de Outeiro ( $\left.\mathrm{n}^{\circ} 36\right)$ apresentou um valor do IC de $28,3^{\circ} \mathrm{C}$. Este fato deve-se ao efeito dos ventos de grande escala (alísios de nordeste) que são predominantes na região, como também da contribuição da morfologia e do tipo de cobertura do solo da ilha, onde na Ilha de Outeiro existem muitas áreas vegetadas e edificações baixas, que permitem uma boa ventilação urbana e pouca impermeabilização do solo, já que existem poucas vias devido o tamanho da Ilha. Na Ilha de Mosqueiro as edificações também são baixas, mas existem mais áreas impermeabilizadas por asfalto e concreto, já que a mesma é bastante utilizada pela população para férias de veraneio e nos finais de semana, o que gera uma maior necessidade de infraestrutura urbana (pavimentação).

$\mathrm{Na}$ Figura 3 tem-se ilustrada a variação característica do índice de Calor na cidade de Belém, em um corte meridional, indo de uma área periférica menos urbanizada para a área central da cidade. O comportamento do corte meridional do IC é análogo ao comportamento de uma ilha de calor, e atingiu uma diferença de $2,2^{\circ} \mathrm{C}$ durante o período de medidas. O fenômeno da Ilha de Calor Urbana foi mensurado por Costa (1998) na década de 1990 e o mesmo encontrou diferenças de temperatura entre a área urbana e a rural de $4,5^{\circ} \mathrm{C}$, e medidas realizadas posteriormente por Silva Junior (2012), que encontrou valores que atingiram até $8,3^{\circ} \mathrm{C}$ de diferença entre a área urbana e a periférica da cidade. Essa variabilidade ocorre, principalmente, devido às características do uso da cobertura do solo. $\mathrm{Na}$ área menos urbanizada, onde há menos edificações, o vento flui com mais facilidade, existem mais áreas com vegetação e menos impermeabilização do solo, o que facilita a evapotranspiração. À medida que se desloca para a área central da cidade essas características vão se invertendo, onde existem mais edificações, menos quantidade de vegetação, maior impermeabilização do solo e obstáculos para reduzir a circulação dos ventos, comportamento este descrito na literatura por Oke (1987).

Howard (1818) observou esse comportamento pela primeira vez na cidade de Londres, onde constatou que a temperatura do ar na área mais densa da metrópole era superior à das áreas periféricas da mesma, atribuindo esse fato ao efeito da população e da queima do carvão para o aquecimento, já que naquela época não existiam edificações altas na cidade.

\section{CONCLUSÕES}

Com base nas análises realizadas as zonas da cidade menos confortáveis termicamente foram a Oeste e Central, devido à baixa quantidade de áreas vegetadas e a grande quantidade de áreas pavimentadas e edificadas. Na zona Central da cidade existe um número maior de edifícios 

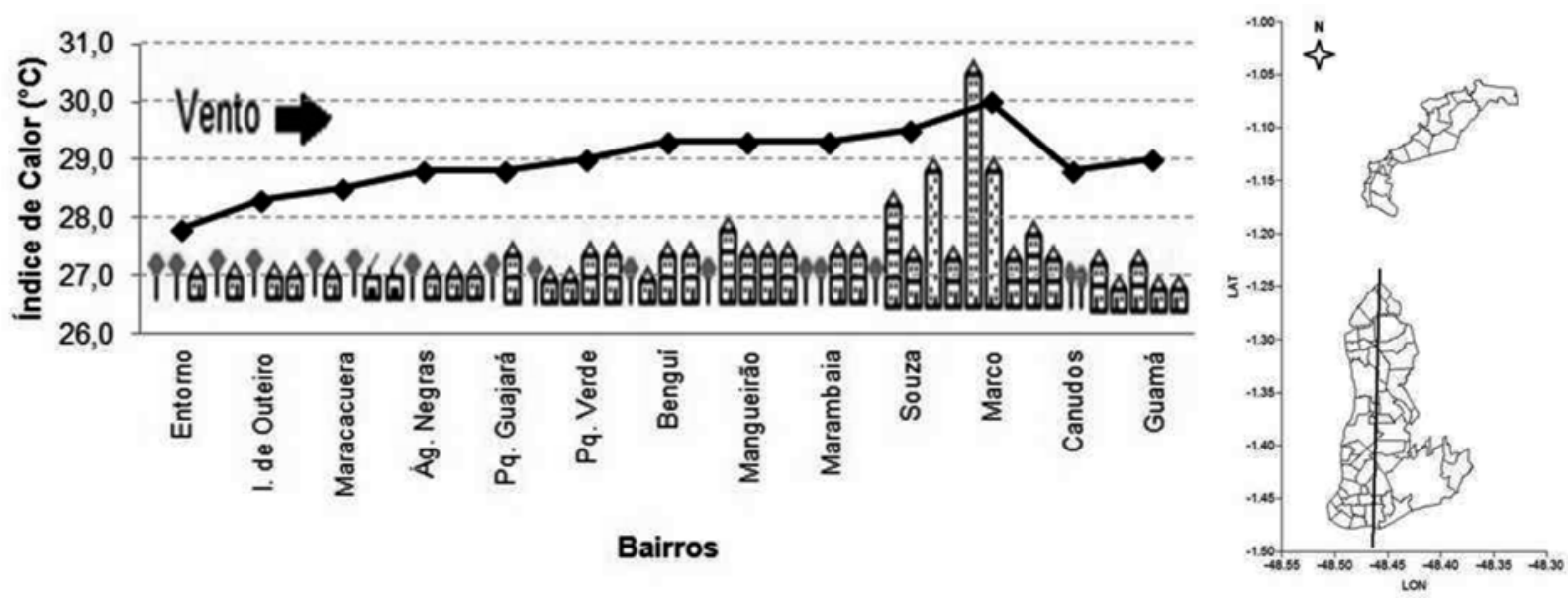

Figura 3 - Seção meridional da variabilidade do IC na cidade de Belém, PA.

altos, que dificultam a circulação do vento e reduzem sua velocidade, o que implica na redução da troca das massas de ar daquela região, e teoricamente propiciaria a formação de microclimas mais desconfortáveis. No entanto, observou-se que o efeito do sombreamento dos edifícios associados à presença de vegetação arbórea nas avenidas nesta parte da cidade, impediu que a mesma fosse a mais desconfortável termicamente. A zona central, especificamente o bairro do Marco $\left(\mathrm{N}^{\circ} 09\right)$ foi o mais desconfortável termicamente (IC = $30,0{ }^{\circ} \mathrm{C}$ ), onde a característica dominante nesta localidade é a pequena quantidade de vegetação e predominando as áreas com pavimentações e edificações. Já o bairro do Curió-Utinga $\left(\mathrm{N}^{\circ} 10\right)$ apresentou a condição de menor desconforto térmico $\left(\mathrm{IC}=27,4^{\circ} \mathrm{C}\right)$, pois grande parte de sua extensão é ocupada pela APA de Belém e por instituições públicas, fato este que impede o desmatamento e o avanço da urbanização para esta área. Ao analisar o comportamento das tipologias sócio-ocupacionais e do IC na Cidade de Belém, observou-se que apesar de todos os bairros estarem dentro da faixa de desconforto térmico, a intensidade deste desconforto não são iguais para os mesmos. A relação entre as tipologias sócio-ocupacionais e o conforto térmico não apresentaram um padrão bem definido, onde nos bairros com a tipologia social "Operário" foi observado o menor valor do IC $\left(27,4{ }^{\circ} \mathrm{C}\right)$ e também o segundo maior valor registrado do IC $\left(29,8^{\circ} \mathrm{C}\right)$, indicando que esta relação está associada aos outros fatores que contribuem para essas diferenças térmicas, como: o tipo de cobertura do solo, a densidade demográfica, o trânsito, a morfologia urbana dos bairros, os materiais empregados nas edificações e as condições atmosféricas. Não foi detectada uma relação clara entre o conforto térmico e as tipologias sócio-ocupacionais na cidade de Belém, apesar da segregação social ser evidente, sendo esta relação melhor explicada pelos tipos de uso da cobertura do solo.

\section{REFERÊNCIAS BIBLIOGRÁFICAS}

BARBIRATO, G. M. A importância da abordagem climática no planejamento urbano. Atmosfera e Sociedade, José C. F. de Oliveira (org.), v.1, Maceió-Al, Edufal, 122 pp. 2010.

CARDOSO, A. C. D. O espaço alternativo: vida e forma urbana nas baixadas de Belém, 265f. Belém: EDUFPA, 265 pp. 2007.

CARDOSO, A. C. D.; LIMA, J. J. F.; SENA, L. F. A.; SANTOS, R. B. N.; CRUZ, S. H. R. A estrutura socioespacial da região metropolitana de Belém: de 1990 a 2000. Novos Cadernos do NAEA, v. 10, n. 01, p.143-183, 2006.

CASTELLS, M. A questão urbana. Rio de Janeiro, Ed. Paz e Terra, 590p. 1983.

CASTELLS; M. The Informational City. Cambridge: Blackwell, 224 pp. 1989.

COSTA, A. C. L. Estudo de Variações Termo-Higrométricas de Cidade Equatorial devido ao Processo de Urbanização. O caso de Belém - PA, 1998, 232f., Tese de Doutorado em Engenharia Ambiental, Universidade de São Paulo, São Carlos, SP. 1998.

DIAS, C. S., DIAS, S. I. S. Belém do Pará: História, Urbanismo e Identidade. Planejamento Urbano e Regional: ensaios acadêmicos do CAUFAG. Cascavel: Smolarek Arquitetura, 2007.

DUMKE, E. M. S. Clima Urbano/Conforto Térmico e Condições de Vida na Cidade - Uma Perspectiva a partir do Aglomerado Urbano da Região Metropolitana de Curitiba (AU-RMC). 2007, 417f., Tese de Doutorado em Meio Ambiente e Desenvolvimento, Universidade Federal do Paraná, Curitiba, 2007.

FANGER, P. O. Thermal Comfort, McGraw-Hill, New York., 245 pp. 1972. 
FROTA, A. B.; SCHIFFER, S. R. Manual de Conforto Térmico. $5^{\text {a }}$ edição. São Paulo: Studio Nobel. São Paulo: Studio Nobel, 243p, 2001.

GOLDREICH, Y. Urban climate studies in Johannesburg, A sub-Tropical city located on a ridge - A review. Atmospheric Environment, v. 26B, n. 3, p. 407-420, 1992.

HOGAN, D. J. Demographic Aspects of Global Environmental Change: What is Brazil Contribution? Human Dimension of Global Environmental Change. Rio de Janeiro, Academia Brasileira de Ciências, p. 17-41, 2001.

HOWARD. L. The Climate of London, Meteorological Observations, Made at Different Places in the Neighborhood of Metropolis. Ed. W. Phillips, Londres. 1818.

IBGE, Instituto Brasileiro de Geografia e Estatística, Cidades. http://www.ibge.gov.br/cidadesat. Acessado em: 07/11/2011. 2010.

JAUREGUÍ, O. E. Aspects of heat-island development in Guadalajara, Mexico. Atmospheric Environment, v. 26B, n.3, p. 391-396. 1992.

LIMA, J. J. F.; MOYSÉS, A. Como Andam Belém e Goiânia. Rio de Janeiro, Letra Capital: Observatório das Metrópoles, 164p., 2009.

MAITELLI, G. T.; ZAMPARONI, C. A. P. G.; LOMBARDO, M. A. Ilha de calor em Cuiabá-MT: Uma abordagem de clima urbano. Encontro Nacional de Estudos sobre Meio Ambiente, p. 561-571, Londrina - PR. 1991.

MARTINS, E. Amazônia, a última fronteira. Rio de Janeiro: Codecri, 257p.1982.

MELLO, C. R.; LIMA, J. M.; SILVA, A. M.; MELLO, J. M.; OLIVEIRA, M. S. Krigagem e inverso do quadrado da distância para interpolação dos parâmetros da equação de chuvas intensas. Revista Brasileira de Ciências do Solo, v.27, 925-933p., 2003.
OKE, T. R. Boundary Layer Climates. 2a Edição, 460 pp. 1987. OLIVEIRA, J. M. G. C.; FRANÇA, C. F.; BORDALO, C. A. L. A verticalização em Belém-Pará, Brasil, nos últimos trinta anos: a produção de espaços segregados e as transformações socioambientais. ANAIS DO X Encontro de Geógrafos da América Latina, 10, 2005, São Paulo-SP, p. 1060910620, 2005.

PALHETA JUNIOR, F. X. Mobilidade residencial em Belém do Pará. In: um olhar sobre os aspectos da infraestrutura e do planejamento urbano em Belém do Pará / Célio Claudio de Queiroz Lobato (org.), Belém: Editora CESUPA, p. 61-112., 2005.

PONTE, M. X. 2003. Rede intra-urbana de água e esgotamento sanitário na cidade de Belém: aspectos históricos, políticos e econômicos da estruturação sanitária. Rio de Janeiro, 2003. Dissertação de Mestrado, Universidade Federal do Rio de Janeiro, 118 pp. 2003.

SILVA JÚNIOR, J. A. Avaliação de parâmetros micrometeorológicos, do conforto e da percepção térmica na área urbana da cidade de Belém- PA. 2012, 157f., Tese de Doutorado em Desenvolvimento Sustentável do Trópico Úmido, Núcleo de Altos Estudos Amazônicos, Universidade Federal do Pará, Belém, 2012.

SILVA JÚNIOR, J. A.; COSTA, A. C. L.; PEZZUTI, J. C. B.; COSTA, R. F.; GALBRAITH, D. Análise da Distribuição Espacial do Conforto Térmico na Cidade de Belém, PA no Período Menos Chuvoso. Revista Brasileira de Geografia Física, v.2, p.218-232, 2012.

STEADMAN, R. G. The Assessment of Sultriness. Part I: A temperature-Humidity Index Based on Human Physiology and Clothing Science. Journal of Applied Meteorology, v.18, p.861-873, 1979.

VILLAÇA, F. Espaço intra-urbano no Brasil. $2^{a}$ Ed., São Paulo: Studio Nobel/ FAPESP/ Lincoln Institute, 2001. 